\title{
A combination of metabolic resistance and high frequency of the 1014F $k d r$ mutation is driving pyrethroid resistance in Anopheles coluzzii population from Guinea savanna of Cameroon
}

Amen N. Fadel ${ }^{1,2+}$, Sulaiman S. Ibrahim ${ }^{3,4^{*}+}$, Magellan Tchouakui ${ }^{1}$, Ebai Terence ${ }^{1}$, Murielle J. Wondji ${ }^{1,3}$, Micareme Tchoupo', Samuel Wanji² and Charles S. Wondji, ${ }^{1,3}$

\begin{abstract}
Background: The scale-up in the distribution of long-lasting insecticidal nets (LLINS) and indoor residual spraying has significantly reduced malaria burden and mortality. However, insecticide resistance, among other factors, is responsible for a recent rebound in malaria transmission in 2015-2016, threatening the progress so far made. As a contribution towards understanding patterns of resistance and its mechanism in the field we characterized a population of Anopheles gambiae (s.l.) from Gounougou, a Guinea savanna of north/central Cameroon.

Results: Indoor collection conducted in September 2017 identified Anopheles coluzzii and Anopheles arabiensis as the unique Anopheles vector species, with abundances of 83 and 17\%, respectively. Analysis of infection with TaqMan assays using heads/thoraces of indoor collected females of An. coluzzii revealed a low Plasmodium falciparum parasite rate of $4.7 \%$. Bioassays conducted with female An. coluzzii revealed extreme resistance, with low mortalities of only $3.75 \pm 1.25 \%, 3.03 \pm 1.59 \%$ and $1.45 \pm 1.45 \%$, respectively, for permethrin, deltamethrin and DDT. In contrast, high susceptibility was obtained with the organophosphates and carbamates, with mortalities in the range of 98-100\%. Synergist assays with piperonyl butoxide (PBO) recovered some susceptibility with increased mortality for permethrin to $14.88 \pm 8.74 \%$, and for deltamethrin to $32.50 \pm 10.51 \%$ ( 27-fold increase compared to mortalities with deltamethrin alone, $\left.x^{2}=29, d f=1, P<0.0001\right)$. These correlated with the results of cone bioassays which revealed complete loss of efficacy of Olyset ${ }^{\circledR}$ Net (0\% mortality) and PermaNet ${ }^{\circledR} 2.0(0 \%$ mortality), and the considerable loss of efficacy of Olyset ${ }^{\circledR}$ Plus (mortality of $2 \pm 2 \%$ ), PermaNet ${ }^{\circledR} 3.0$ side panel (mortality of $2 \pm 2 \%$ ) and PermaNet3.0 $0^{\circledR}$ roof (mortality of $16 \pm 5.1 \%$ ). Time-course bioassays conducted with deltamethrin established a high intensity of resistance, with $\mathrm{LT}_{50}$ of 309.09 ( $95 \%$ Cl 253.07-393.71, Fiducial), and a resistance ratio of 93.09 compared with the fully susceptible Ngoussou laboratory colony. TaqMan genotyping revealed a high frequency of the $1014 \mathrm{~F}$ allele (65.25\%) in the An. coluzzii populations. Sequencing of a fragment of the voltage-gated sodium channel identified a single An. arabiensis female harbouring the $1014 \mathrm{~S} k d r$ mutation.
\end{abstract}

\footnotetext{
*Correspondence: sulaimansadi.ibrahim@|stmed.ac.uk

${ }^{\dagger}$ Amen Nakebang Fadel and Sulaiman S. Ibrahim contributed equally to

this work

${ }^{3}$ Vector Biology Department, Liverpool School of Tropical Medicine

(LSTM), Liverpool L3 5QA, UK

Full list of author information is available at the end of the article
}

(c) The Author(s) 2019. This article is distributed under the terms of the Creative Commons Attribution 4.0 International License (http://creativecommons.org/licenses/by/4.0/), which permits unrestricted use, distribution, and reproduction in any medium, provided you give appropriate credit to the original author(s) and the source, provide a link to the Creative Commons license, and indicate if changes were made. The Creative Commons Public Domain Dedication waiver (http://creativecommons.org/ publicdomain/zero/1.0/) applies to the data made available in this article, unless otherwise stated. 
Conclusions: This finding of high pyrethroid and DDT resistance in An. coluzzii from north-central Cameroon is a major obstacle to malaria control using pyrethroid bednets and indoor residual spraying with DDT.

Keywords: Anopheles coluzzii, Deltamethrin, Permethrin, DDT, Metabolic resistance, kdr, Cameroon

\section{Background}

Malaria is one of the major life-threatening diseases in the world, with 435,000 deaths in 2017 [1], of which 92\% occurred in the WHO African region. It is estimated that every two minutes a child dies from this preventable and curable disease [2]. Despite the huge investment in malaria control, conservative estimates suggest that malaria cases increased globally by two million in 2017 compared to 2016 [1, 2]. Insecticide resistance is one of the major obstacles hindering the effectiveness of the core malaria control tools, for example, long-lasting insecticidal nets (LLINs) and indoor residual spraying (IRS) $[3,4]$.

In Cameroon malaria is endemic, with some variation in the transmission intensity in specific areas, such as highland, Sahel and Guinea savanna [5-7], with Plasmodium falciparum as the most common species [8-11]. Malaria transmission in the north of Cameroon is characterized by seasonal patterns linked to rainy season, which covers the period from August to October [6]. In northern Cameroon, the main malaria vectors belong to the An. gambiae complex, Anopheles funestus group, Anopheles pharoensis [5, 12-15] and recently Anopheles rufipes $[16,17]$. Members of the An. gambiae complex largely distributed in northern Cameroon are An. arabiensis, An. coluzzii and An. gambiae (s.s.) [18, 19]. It has been shown in studies conducted across four ecogeographical zones of Cameroon, from the northern savanna region to southern forested regions, that in most urban settings An. coluzzii (the M molecular form) densities are greater than those of An. gambiae (s.s.) (the S form), which is more prevalent in peri-urban and rural settings $[20,21]$.

Intense use of the pyrethroid insecticides in northern Cameroon for crop protection by farmers $[13,15]$ and malaria vector control through large scale insecticidetreated nets (ITNs) and LLIN distribution programmes [22] could possibly have placed selective pressure on the malaria vectors [4] to develop more resistance. Starting from 2017, Cameroon has scaled-up the distribution of ITNs and IRS in the northern part of the country [23], including Gounogou. This, in addition to the use of organochlorides, carbamates and pyrethroids in Gounougou cotton farms [13, 19] could have resulted in increased resistance to public heath insecticides.

The two major resistance mechanisms, metabolic and $k d r$-based, have been increasingly reported in $A n$. gambiae complex and only metabolic mechanism in $A n$. funestus (s.s.) from northern Cameroon [19]. Metabolicbased resistance is the major mechanism in the north tropical regions of Cameroon, with the temporal distribution of the DDT/pyrethroid 119F-GSTe2 resistant allele detected in An. funestus (s.s.) [15]. Additionally, overexpressed cytochrome P450s are implicated in conferring increased tolerance to pyrethroids in An. funestus and An. gambiae (s.l.), e.g. CYP4G16 has been shown to be involved in deltamethrin tolerance in An. arabiensis mosquito populations from northern Cameroon [15, 24].

The presence of the $1014 \mathrm{~F}$ and $1014 \mathrm{~S} k d r$ mutations in An. coluzzii and An. gambiae populations from Cameroon was first established by Etang et al. [25]. These mutations have since then spread across the country, from the southern wet forest to the northern dry savanna [19]. Various studies have revealed a widespread distribution of the $k d r$ mutations in pyrethroid and DDT resistant populations of An. gambiae (s.l.) in different localities in northern Cameroon, including Gounougou [13, 14, 26-28].

Among the two major malaria vector species involved in transmission in Gounougou, only An. funestus has been sufficiently characterized, whereas little is known about An. gambiae complex. Although vector control is highly prioritized in the Cameroonian national strategic plan for malaria control, a lack of evidence on the molecular basis of metabolic resistance in An. gambiae (s.l.) from northern Cameroon is hindering the implementation of evidence-based control tools and resistance management. To support malaria vector control in northern Cameroon, we characterized a population of An. gambiae (s.l.) from Gounougou, a village in the Guinea savanna of Lagdo. An. coluzzii and An. arabiensis were found sympatric at Gounougou, with the former in higher proportion. The An. coluzzii exhibited high resistance to the pyrethroids and DDT. A high frequency of the 1014F $k d r$ mutation was detected in $A n$. coluzzii, while the mutation was absent in An. arabiensis. In contrast, a single An. arabiensis female was found harbouring the $1014 \mathrm{~S} k d r$ allele.

\section{Methods}

\section{Sampling site and mosquito collection}

Mosquitoes were collected at Gounougou $\left(9^{\circ} 03^{\prime} 00^{\prime \prime} \mathrm{N}\right.$, $13^{\circ} 43^{\prime} 59^{\prime \prime} \mathrm{E}$ ), a town located at Lagdo, in northern Cameroon (Fig. 1). This locality lies along the River Benoué, in an area with cotton farming and rice cultivation, made 


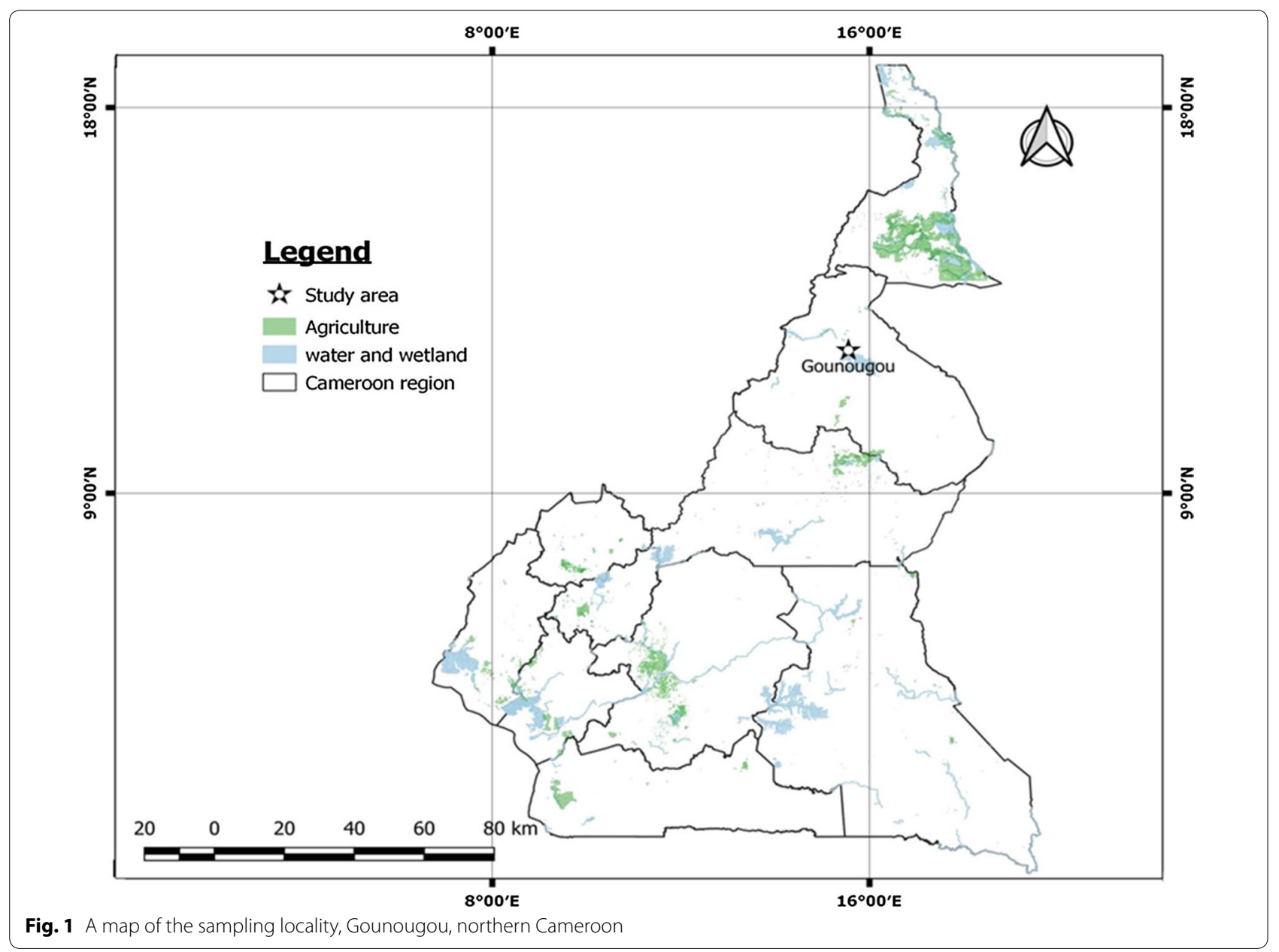

possible by the presence of a hydroelectric dam. Farmers at Gounougou have a long tradition of using DDT and pyrethroid insecticides [26]. The climate of Gounougou is characterized by a short rainy season from May to September (mean annual rainfall of 900 to $1000 \mathrm{~mm}$ ) and a long dry season from October to April. Between 2011 and 2016, almost all households at Gounougou had been provided with LLINs by the Cameroon National Malaria Control Programme [19]. PermaNet ${ }^{\circledR} 2.0$ containing deltamethrin and Olyse ${ }^{\circledR}$ Net containing permethrin were distributed at Gounougou with a coverage of $~ 80 \%$ in 2016 and 85\% in 2018.

Blood-fed female Anopheles mosquitoes resting indoors were collected between 06:00 and 08:00 h in August 2017. This was done using Prokopack electrical aspirators (John W. Hook, Gainesville, FL, USA). Mosquitoes were kept in paper cups in cooling boxes during transport to the insectary at OCEAC, Cameroon. The previously described forced-egg laying method [29] was used to generate $F_{1}$ progenies in $1.5 \mathrm{ml}$ microcentrifuge tubes containing a slightly wet filter paper. Eggs were stored at room temperature for up to 2 days, and then transferred into small paper cups to hatch. Larvae were transferred to bowls containing water for rearing. Mosquitoes were maintained under standard insectary conditions, with a temperature $25{ }^{\circ} \mathrm{C}$, relative humidity of $70-80 \%$ and $12: 00 \mathrm{~h}$ light:dark cycles. Emerged adults were maintained on $10 \%$ sucrose in cages, and randomly mixed for insecticide bioassays.

\section{Mosquito species identification to the species level}

A total of 209 female Anopheles mosquitoes were collected at Gounougou, out of which 202 (96.65\%) were identified morphologically according to the keys of Gillies \& de Meillon [30] and Gillies \& Coetzee [31]. These comprised 195 An. gambiae (s.l.) (96.5\%) and 7 An. rufipes (3.5\%). Only $123 \mathrm{~F}_{0}$ An. gambiae (s.l.) which laid eggs successfully with positive hatching were identified to the species level using PCR. It was the larvae of these PCR-identified females which were pooled to generate $F_{1}$ progenies. The Livak method [32] was used to extract 
DNA and identification to species level was carried out using SINE200 PCR for An. gambiae complex [33].

\section{Estimation of Plasmodium spp. infection rates}

The sporozoite infection rate was determined using heads/thoraces of 106 blood-fed $F_{0}$ females collected indoors. These females were allowed to lay eggs before being dissected. The TaqMan assay was carried out as previously established [34] using the real-time PCR MX 3005 (Agilent, Santa Clara, CA, USA). One microliter of DNA was used as a template in a 3-step PCR with denaturation at $95{ }^{\circ} \mathrm{C}$ for $10 \mathrm{~min}$, followed by 40 cycles of $95{ }^{\circ} \mathrm{C}$ for $15 \mathrm{~s}$ and $60{ }^{\circ} \mathrm{C}$ for $1 \mathrm{~min}$. The primers PlasF (5'-GCT TAG TTA CGA TTA ATA GGA GTA GCT TG-3') and PlasR (5'-GAA AAT CTA AGA ATT TCA CCT CTG ACA-3') were used together with two probes labelled with flurorophores FAM (Falcip+ 5'-TCT GAA TAC GAA TGT $C-3^{\prime}$ ) to detect $P$. falciparum, and HEX $\left(\mathrm{OVM}+5^{\prime}\right.$-CTG AAT ACA AAT GCC-3') to detect $P$. ovale, $P$. vivax and $P$. malariae. Two $P$. falciparum samples and a mix of $P$. ovale, $P$. vivax and $P$. malariae were used as positive controls. A nested PCR of Snounou et al. [35] was performed for all the positive samples to validate the TaqMan assay results.

\section{Insecticide susceptibility bioassays}

To establish resistance profile of the An. gambiae (s.l.) populations, various insecticides used in public health control of malaria vectors were tested in bioassays following the protocol of the World Health Organization [36]. Two- to four-day-old, unfed $\mathrm{F}_{1}$ and $\mathrm{F}_{2}$ female $A n$. coluzzii were exposed for $1 \mathrm{~h}$ to diagnostic doses of the following insecticides: the type I pyrethroid permethrin $(0.75 \%)$, and the type II pyrethroid deltamethrin $(0.05 \%)$; the organochlorine, DDT (4\%); the carbamates, bendiocarb $(0.01 \%)$ and propoxur $(0.1 \%)$; and the organophosphates, malathion (5\%) and fenitrothion (5\%). Four replicates of approximately 20-25 mosquitoes per tube (except for deltamethrin, $F_{1}$ tested with three replicates) were exposed to impregnated papers for $1 \mathrm{~h}$ and then transferred to holding tubes. Mosquitoes were supplied with $10 \%$ sucrose and mortalities were recorded at 24 $\mathrm{h}$ after exposure. The control comprised 25 mosquitoes exposed to untreated papers. Populations were considered susceptible to an insecticide where mortality was $>98 \%$, suspected to be resistant (moderately resistant) where mortality was between $90-98 \%$, and resistant where mortality was found to be $<90 \%$ [36].

\section{Synergist bioassay with piperonyl butoxide (PBO)}

To identify the possible enzyme systems involved in pyrethroids and/or DDT resistance synergist bioassays were conducted. Due to a low number of mosquitoes, the $F_{1}$ progenies were allowed to mate and were blood-fed to generate $F_{2}$ populations. Two- to four-day-old $F_{2}$ females were first exposed to $4 \% \mathrm{PBO}$ for $1 \mathrm{~h}$, followed by exposure to either $0.75 \%$ permethrin, $0.05 \%$ deltamethrin or $4 \%$ DDT for $1 \mathrm{~h}$. Mortality was recorded $24 \mathrm{~h}$ after exposure and the differences in mortalities between synergized and non-synergized experiments were compared using a Chi-square test of significance.

\section{Test of bednet efficacy using a cone assay}

Cone bioassays were conducted according to the WHO procedure [36] using unfed, 3- to 4-day-old $F_{2}$ females of An. coluzzii. Five replicates of ten mosquitoes were placed in plastic cones attached to four standard insecticide bednets: the Olyset ${ }^{\circledR} \mathrm{Net}$ (containing 2\% permethrin), OlysetPlus ${ }^{\circledR}$ Net (containing 2\% permethrin combined with $1 \%$ of the synergist PBO), PermaNet ${ }^{\circledR} 2.0$ (containing 1.4-1.8 g/ $/ \mathrm{kg} \pm 25 \%$ deltamethrin), and PermaNet ${ }^{\circledR} 3.0$ [both the side panel (containing 2.1-2.8 g/ $\mathrm{kg} \pm 25 \%$ deltamethrin) and the roof (containing $4.0 \mathrm{~g} /$ $\mathrm{kg} \pm 25 \%$ deltamethrin, combined with $25 \mathrm{~g} / \mathrm{kg} \pm 25 \%$ of PBO)]. Fresh, unused PermaNets and OlysetNets were respectively provided by Vestergaard, Lausanne, Switzerland and Sumitomo Chemical Plc, London, UK. Three replicates of ten mosquitoes were exposed to an untreated net as control. For each test, the exposure time was $3 \mathrm{~min}$ and mosquitoes were immediately transferred to paper cups and supplied with $10 \%$ sucrose. Mosquitoes that were knocked down were recorded after $60 \mathrm{~min}$ and mortality recorded $24 \mathrm{~h}$ after exposure.

\section{Establishment of resistance intensity}

To assess the strength of resistance, a time course bioassay was conducted using deltamethrin with $\mathrm{F}_{2} A n$. coluzzii populations. The protocol followed the procedure as outlined for the conventional bioassays only that exposure time was varied, using exposures of $60,90,120$, 180 and $240 \mathrm{~min}$. The time required to kill $50 \%$ of the experimental mosquitoes $\left(\mathrm{LT}_{50}\right)$ was calculated using the glm function of MASS package ( $\mathrm{R}$ v.3.5.0). The Ngoussou females were also exposed to deltamethrin in a timecourse bioassay at 2.5, 5, 10, 15, 30, 45 and $60 \mathrm{~min}$, and $\mathrm{LT}_{50}$ was calculated. Resistance intensity was estimated from the ratio of the $\mathrm{LT}_{50}$ of the Gounougou populations to that of Ngoussou. Measurement of resistance intensity using $5 \times$ and $10 \times$ insecticide concentrations, as recommended by the WHO, was not undertaken due to unavailability of the papers.

\section{Investigation of the role of the $1014 \mathrm{~F}$ knockdown resistance mutation in pyrethroid/DDT resistance}

To establish the frequency of $k d r$ mutations in field caught An. gambiae (s.l.) populations, a TaqMan assay 
was performed to genotype the L1014F $k d r$ mutation according to the procedure of Bass et al. [37]. Ten microliters containing $1 \times$ Sensimix (Bioline, TN, USA), $80 \times$ primer/probe mix and $1 \mu \mathrm{l}$ of template DNA were used. The primers $k d r_{-} \mathrm{F}$ ( $5^{\prime}$-CAT TTT TCT TGG CCA CTG TAG TGA T- $\left.3^{\prime}\right)$ and $k d r_{-} \mathrm{R}\left(5^{\prime}\right.$-CGA TCT TGG TCC ATG TTA ATT TGC A-3') were used without modififcation. Probes were labelled with two specific fluorophores, FAM and HEX: FAM to detect the resistant allele [ $\left(5^{\prime}-\right.$ ACG ACA AAA TTT C-3' for 1014F $k d r)$, (5'-ACG ACT GAA TTT C-3 $3^{\prime}$ for $\left.1014 \mathrm{~S} k d r\right)$ ] and HEX (5'-CTT ACG ACT AAA TTT $C-3^{\prime}$ ) to detect the susceptible allele. The assay was performed on an Agilent MX3005 real-time PCR machine with cycling conditions of $95^{\circ} \mathrm{C}$ for $10 \mathrm{~min}$, followed by 40 cycles of $95{ }^{\circ} \mathrm{C}$ for $15 \mathrm{~s}$ and $60^{\circ} \mathrm{C}$ for 1 min.

To assess the genetic diversity and detect potential signatures of selection acting on the voltage-gated sodium channel, a portion of this gene spanning exon 20 was sequenced in $15 \mathrm{An}$. coluzzii and $14 \mathrm{An}$. arabiensis females. Initial fragment amplification was carried out using primers $k d r \mathrm{CL}-\mathrm{F}$ (5'-AAA TGT CTC GCC CAA ATC AG-3') and $k d r C L-R\left(5^{\prime}-\right.$ GCA CCT GCA AAA CAA TGT CA-3') described previously [38]. The $15 \mu \mathrm{l}$ PCR mixture comprised $1.5 \mu \mathrm{l}$ of $10 \times$ Buffer A (Kapa Biosystems, Wilmington, MA, USA), $0.75 \mu \mathrm{l}$ of $25 \mathrm{mM}$ $\mathrm{MgCl}_{2}, 0.12 \mu \mathrm{l}$ of $25 \mathrm{mM}$ dNTPs, $0.12 \mu \mathrm{l}$ of Kapa Taq DNA polymerase, $0.51 \mu \mathrm{l}$ each of the forward and reverse primer, $10.49 \mu \mathrm{l}$ of double distilled water $\left(\mathrm{ddH}_{2} \mathrm{O}\right)$ and 1 $\mu \mathrm{l}$ of genomic DNA template. Cycling condition were as follows: $95{ }^{\circ} \mathrm{C}$ for $5 \mathrm{~min}$, followed by 35 cycles of $94{ }^{\circ} \mathrm{C}$ for $30 \mathrm{~s}, 57^{\circ} \mathrm{C}$ for $30 \mathrm{~s}$ and $72{ }^{\circ} \mathrm{C}$ for $45 \mathrm{~s}$, followed by a final extension step at $72{ }^{\circ} \mathrm{C}$ for $10 \mathrm{~min}$. PCR products were cleaned up using Exonuclease I (Exo I) and Shrimp Alkaline Phosphate (Exo-SAP protocol) according to the protocol of New England Biolabs (NEB, MA, USA). Purified PCR products were sequenced on both strands using the above primers.

Sequences were corrected manually using BioEdit v.7.2.1 [39] and aligned with ClustalW. Analysis of genetic parameters of polymorphism was carried out using theDnaSP v.5.10 [40]. Different sequences/haplotypes were compared by constructing a maximum likelihood phylogenetic tree, using MEGA v.7.0 [41].

\section{Results}

\section{Mosquito species composition}

All mosquitoes collected indoors were morphologically identified as An. gambiae (s.l.) and An. rufipes. The 123 females which laid eggs were PCR-identified as $83 \%$ An. coluzzii (102 females) and $17 \%$ An. arabiensis (21 females).

\section{Sporozoite infection rate}

Out of 106 An. gambiae (s.l.) females analysed by TaqMan assays (85 An. coluzzii and 21 of An. arabiensis), only $4.7 \%$ of the An. coluzzii (4/106) were infected with P. falciparum. These four positive samples were validated by nested PCR. None of the An. arabiensis mosquitoes were infected.

\section{Insecticide resistance status of $A$. coluzzii populations} Only An. coluzzii populations ( $\mathrm{F}_{1}$ and $\mathrm{F}_{2}$ generations) were used for bioassays. Anopheles arabiensis were not used due to the low number during collection, and low hatching rate/larvae survival. The An. coluzzii populations were highly resistant to pyrethroids, with mortalities on exposure to permethrin of $3.75 \pm 1.25 \%$ and $8.75 \pm 2.23 \%$ for the $F_{1}$ and $F_{2}$ progenies, respectively (Fig. 2a, b). Higher resistance was observed with the type II pyrethroid-deltamethrin, with mortalities for the $\mathrm{F}_{1}$ and $\mathrm{F}_{2}$ progenies of $3.03 \pm 1.59 \%$ and $1.19 \pm 1.19 \%$, respectively. High resistance was also seen with DDT (mortality of $1.45 \pm 1.45 \%$ for $F_{1}$ progenies, and no mortality at all with the $F_{2}$ progenies). However, all mosquitoes were susceptible to carbamates, with mortalities for bendiocarb of $98.81 \pm 1.19 \%$ for the $F_{1}$ progenies, and $100 \%$ for propoxur with the $\mathrm{F}_{2}$ progenies. The same pattern of susceptibility was obtained with organophosphates, with malathion producing $100 \%$ mortality for $\mathrm{F}_{1}$ progenies and fenitrothion exhibiting a mortality of $98.75 \pm 1.25 \%$ for the $F_{2}$ progenies.

\section{Synergist bioassay for pyrethroid and DDT resistance}

To investigate the possible role of the cytochrome P450s in the observed pyrethroid and DDT resistance, the $\mathrm{F}_{2}$ An. coluzzii were pre-exposed to PBO followed by permethrin, deltamethrin and DDT separately. Compared to results from conventional bioassays above (mortality of $8.75 \pm 2.23 \%$ ), no significant recovery of susceptibility was observed for permethrin, with mortality increasing to only $14.88 \pm 8.74 \%$ following pre-exposure to $\mathrm{PBO}$ (Fig. 3a). A significant increase in mortality was observed in mosquitoes exposed to PBO and deltamethrin (mortality of $32.50 \pm 10.51 \%)$ compared with those exposed to deltamethrin alone $\left(x^{2}=29, d f=1, P<0.0001\right)$. This is, on average, a 27 -fold increase. For DDT, there was no major change in mortality following $\mathrm{PBO}$ pre-exposure $(1.19 \pm 1.19 \%)$. No mortality was recorded in control mosquitoes exposed to the $\mathrm{PBO}$ alone.

\section{Determination of bednet efficacy}

To evaluate efficacy of the long-lasting insecticidal nets, cone bioassays were carried out. Initially, a $100 \%$ mortality was observed with the fully susceptible An. coluzzii 

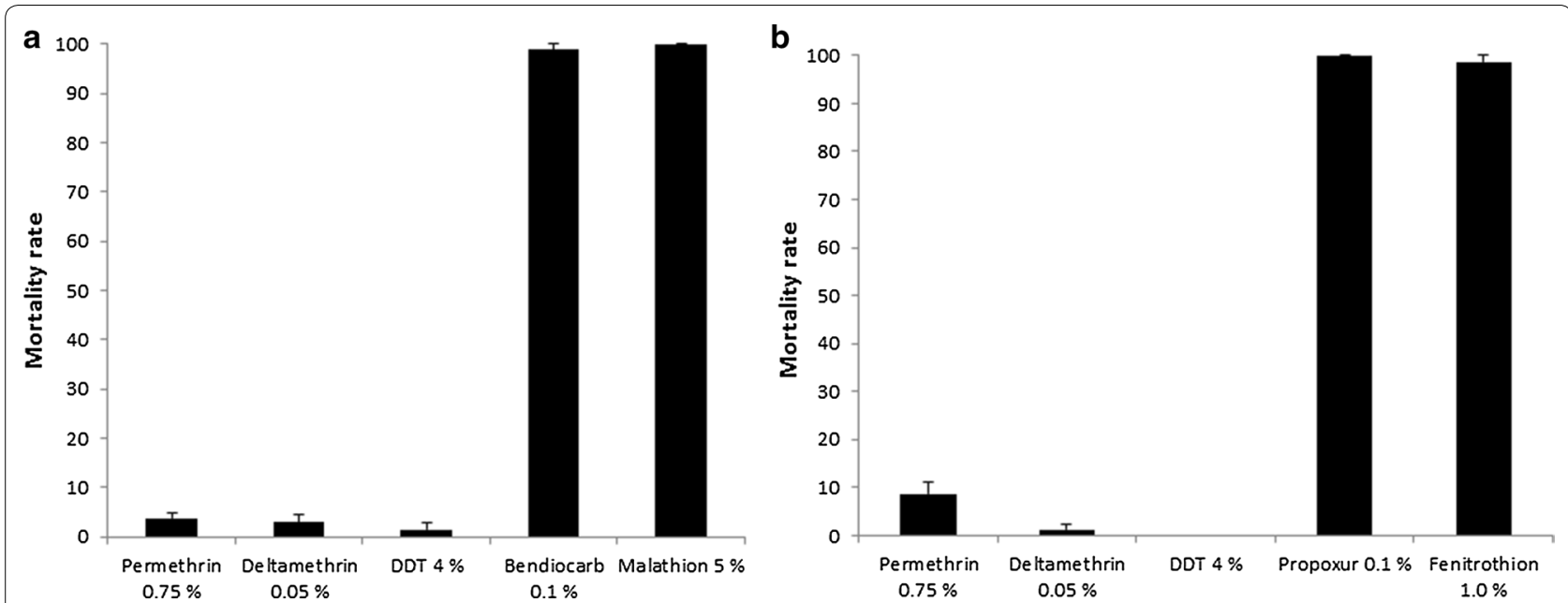

Fig. 2 Results of WHO insecticides susceptibility test. a Susceptibility profile of female Gounougou An. coluzzii ( $F_{1}$ population) following exposure to various public health insecticides. $\mathbf{b}$ Susceptibility profile of Gounougou female An. coluzzii ( $F_{2}$ population). Error bars represent standard error of the mean
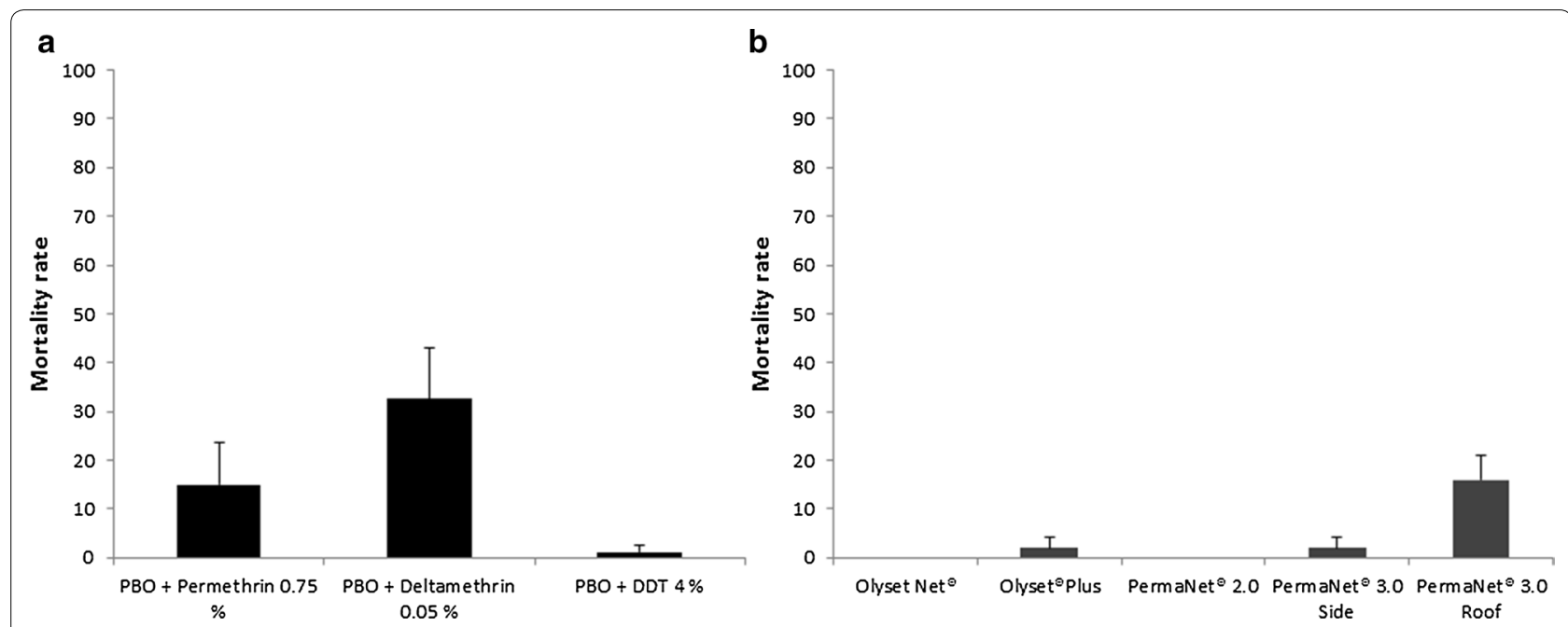

Fig. 3 Results of synergist bioassays and cone bioassays. a Effect of pre-exposure to piperonyl butoxide (PBO) on mortality in female $F_{2}$ An. coluzzii. b Effect of exposure to various LLINs on mortality in female An. coluzzii populations. Error bars represent standard error of the mean

(Ngoussou laboratory colony) with PermaNet ${ }^{\circledR} 2.0$, and a high mortality of $88 \pm 3.74 \%$ with Olyset ${ }^{\circledR}$ Net. On testing the Gounougou population $\left(\mathrm{F}_{2}\right.$ An. coluzzii), an extensive loss of efficacy of Olyset ${ }^{\circledR}$ Net and Permanat ${ }^{\circledR} 2.0$ was observed, with $0 \%$ mortality $24 \mathrm{~h}$ after exposure (Fig. 3b). Low mortalities were also obtained with the side panels of PermaNet ${ }^{\circledR} 3.0(2 \pm 2 \%)$ and Olyset ${ }^{\circledR}$ Plus $(2 \pm 2 \%)$ with the $\mathrm{F}_{2}$ populations. Exposure to the roof of PermaNet ${ }^{\circledR} 3.0$ increased the mortalities to $16 \pm 5.1 \%$ indicating a limited role of cytochrome P450s in the deltamethrin resistance. No mortality was obtained with the $F_{2}$ control populations exposed to untreated bednets.

\section{Intensity of pyrethroid resistance in An. coluzzii populations}

Time course bioassays confirmed intense deltamethrin resistance in the Gounougou An. coluzzii (Fig. 4a). Mortalities of less than $5 \%$ were obtained after $2 \mathrm{~h}$ of exposure and less than $20 \%$ after $4 \mathrm{~h}$. This led to a very high $\mathrm{LT}_{50}$, estimated as 309.09 (95\% CI: 253.07-393.71, Fiducial) (Fig. 4b). The $\mathrm{LT}_{50}$ for Ngoussou colony was calculated as $3.32 \mathrm{~min}$ (CI: 2.67-3.97) from a previous study [42]. Thus, a resistance intensity for the Gounougou population compared with Ngoussou was calculated as 93.1. 


\section{Presence of the knockdown resistance mutation}

To establish the frequency of $1014 \mathrm{~F} k d r$ mutation in the Gounougou population, a TaqMan genotyping was carried out using DNA samples extracted from $59 \mathrm{~F}_{0} A n$. coluzzii and $18 \mathrm{~F}_{0}$ An. arabiensis. The $1014 \mathrm{~F} k d r$ mutation was only found in the An. coluzzii population, at a high frequency of $65.25 \%$. The frequency of this $k d r$ was marginally higher in the heterozygote individuals, at $45.7 \%$ (27/59), compared to the homozygous resistant individuals $(42.37 \%, 25 / 59)$. The distribution of $k d r$ genotype is shown in Table 1. The susceptible allele 1014L was detected in both species, with 7 An. coluzzii homozygous susceptible $(7 / 59,11.87 \%)$, and all the $A n$. arabiensis
$100 \%$ homozygote susceptible (18/18). The L1014S $k d r$ mutation was not investigated using TaqMan assay.

\section{Polymorphism analysis of the An. coluzzii voltage-gated sodium channel (VGSC)}

Analysis of 498-bp fragments of the VGSC spanning the 1014 codon from $15 \mathrm{An}$. coluzii indicated the occurrence of six distinct haplotypes in Gounougou females. The genetic diversity parameters of fragment of the VGSC gene are provided in Table 2. Overall, six polymorphic sites were present in the sequenced fragment with a haplotype diversity of 0.701 . Four of six haplotypes $(\mathrm{H} 1, \mathrm{H} 2$, H4 and H5) had 1014F resistant alleles at high frequency
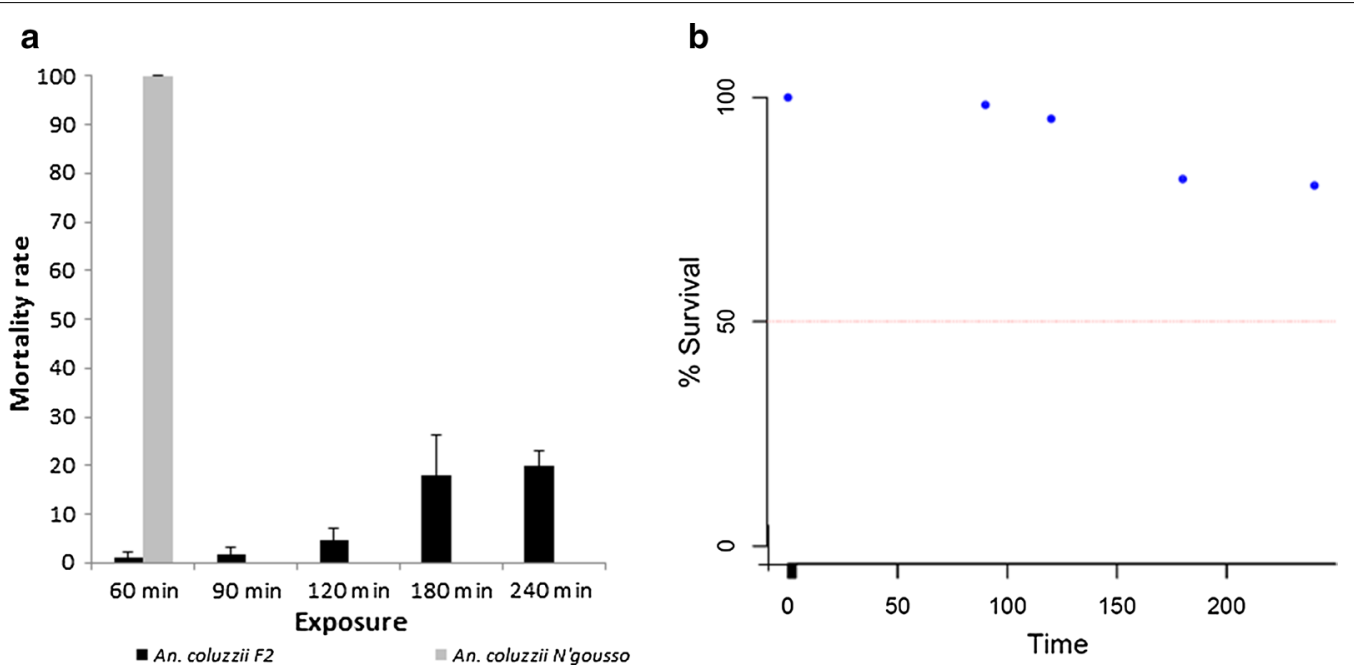

Fig. 4 Results of the time-course bioassay with deltamethrin. a Susceptibility profile of female An. coluzzii population in Gounougou and An. coluzzii N'gousso strain to deltamethrin (0.05\%) at different time points. Error bars represent standard error of the mean. b Probit plot for estimation of resistance intensity in An. coluzzii populations

Table 1 Genotypes and allele frequency of the 1014F kdr mutation in the Gounougou An. coluzzii population

\begin{tabular}{lllllllll}
\hline Population & \multicolumn{2}{l}{ Genotype } & & & & & Allele \\
\cline { 2 - 7 } & SS & RR & RS & Total & $2 N$ & $f(S)$ & $f(R)$ \\
\hline An. coluzzii & 7 & 25 & 27 & 59 & 118 & 0.3475 & 0.6525 \\
An. arabiensis & 18 & 0 & 0 & 18 & 36 & 1 & 0 \\
\hline
\end{tabular}

Abbreviations: RR, homozygous resistant; RS, heterozygous resistant; SS, homozygous susceptible

Table 2 Summary statistics for polymorphism and diversity in the voltage-gated sodium channel gene of Gounougou An. coluzzii and An. arabiensis

\begin{tabular}{|c|c|c|c|c|c|c|c|c|c|}
\hline Species & Gene & $n$ & $\mathrm{~S}$ & h & $\mathrm{Hd}$ & $\pi$ & TajimaD & FuLiD* & FuLiF* \\
\hline An. coluzzii & Exon 20 & 30 & 6 & 6 & 0.701 & 0.00381 & $-0.384^{\mathrm{ns}}$ & $1.2143^{\mathrm{ns}}$ & $0.8598^{\text {ns }}$ \\
\hline An. arabiensis & Exon 20 & 28 & 6 & 5 & 0.27 & 0.00108 & $-1.9719^{\text {ns }}$ & $-2.5946^{\mathrm{ns}}$ & $-2.8039^{\text {ns }}$ \\
\hline
\end{tabular}

Abbreviations: $n$, number of sequences; $S$, number of polymorphic sites; $h$, haplotype; $H d$, haplotype diversity; $\pi$, nucleotide diversity; TajimaD, Tajima's $D$ statistic; FuLiD*, Fu and Li's D* statistic; FuLiF*, Fu and Li's F* statistic; ns, not significant 
of $90 \%(27 / 30)$ while the two remaining ones had $1014 \mathrm{~L}$ susceptible alleles at lower frequency of $10 \%(3 / 30)$. Among these, $\mathrm{H} 1$ and $\mathrm{H} 3$ were the two major haplotypes containing the $1014 \mathrm{~F}$ resistant allele at high frequency of $46.66 \%(14 / 30)$ and 30\% (9/30), respectively (Fig. 5a-c). The neutrality test of Tajima's D had a negative value for An. coluzzii but it was not significant.

Phylogenetic analysis of the above six haplotypes using maximum likelihood indicated that there were two distinct haplotype groups, with one carrying the $1014 \mathrm{~F}$ resistant allele and the other containing the $1014 \mathrm{~L}$ susceptible allele (Fig. 5d). The comparison of the Gounougou haplotypes with four $k d r$ bearing haplotypes previously detected across Africa revealed that only the second major haplotype H3 from Gounougou belongs to the H1-1014F resistant haplotype, predominant in West/ Central Africa [38]. Haplotype network tree analysis showed that haplotypes $\mathrm{H} 3, \mathrm{H} 4$ and $\mathrm{H} 5$ are separated by 1 or 2 mutational steps from the ancestor haplotype $\mathrm{H} 1$ which also belonged to the resistant allele (Fig. 5d). This observation suggests an independent occurrence of the 1014F haplotype in Gounougou, potentially from local selection. Haplotypes H2 and H6 carrying the 1014L susceptible allele are the most isolated to the predominant haplotype $\mathrm{H} 1$ with 3 and 4 mutational steps, respectively.

Analysis of the haplotype network of the $k d r$ gene based on L1014F alleles of 460-bp from 14 An. arabiensis showed that there are five haplotypes in total (Fig. 6d), with a very low polymorphism and low haplotype diversity, of only 0.27 (Table 2). Tajima's neutrality test had

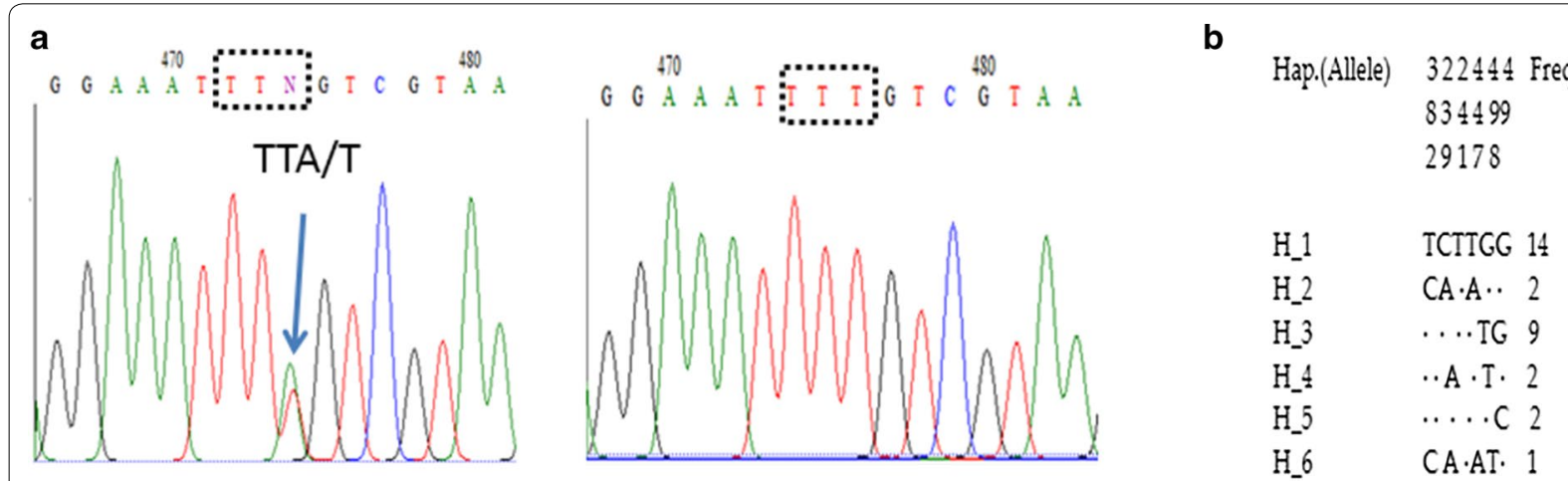

C

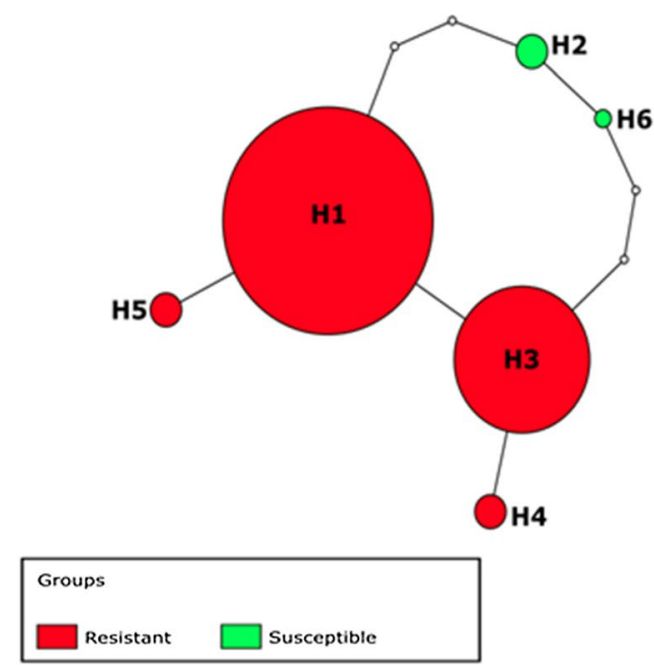

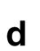

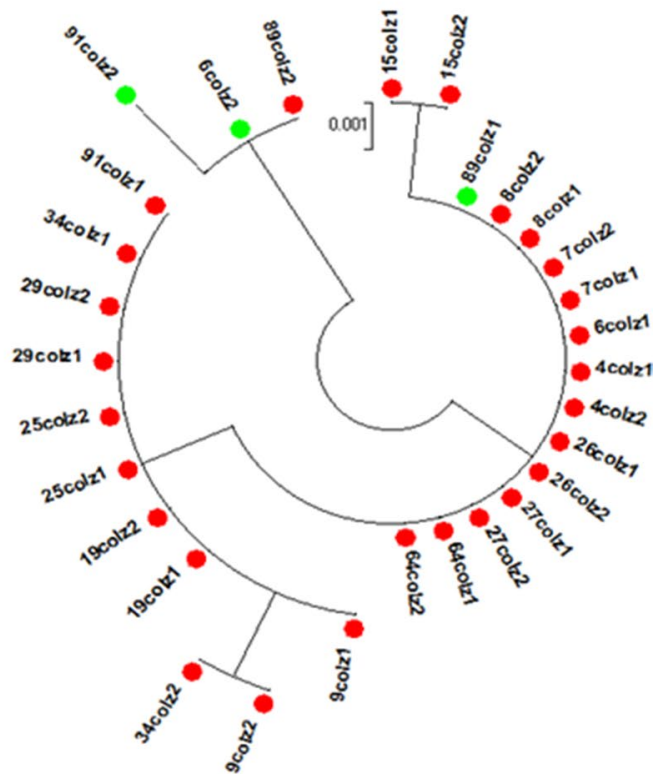

Fig. 5 Genetic diversity of fragment of VGSC spanning exon 20 in An. coluzzii. a Sequencing traces showing the polymorphic position for the $1014 \mathrm{~F}$ kdr mutation. $\mathbf{b}$ Haplotype diversity patterns of the 498-bp fragment of VGSC. c TCS and tCsBU haplotype network showing a low polymorphism of exon 20. d Phylogenetic tree analysis of the VGSC fragment. Green dots represent the susceptible haplotypes and the red dots the resistant haplotypes 


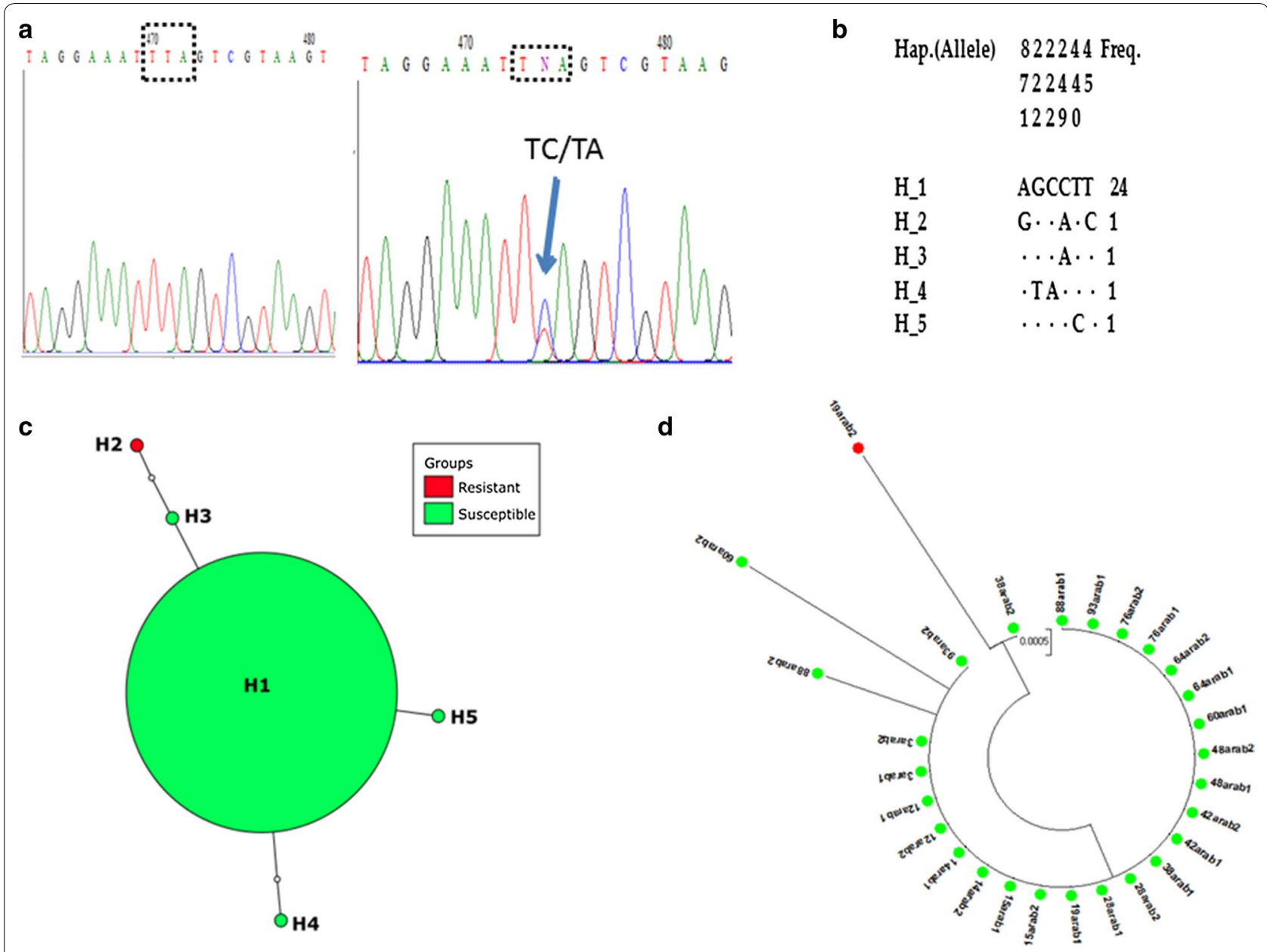

Fig. 6 Genetic diversity of fragment of VGSC spanning exon 20 in An. arabiensis. a Sequencing traces showing the polymorphic position 441 generating the $1014 \mathrm{~S}$ kdr mutation. b Haplotype diversity patterns of the 460-bp fragment in Gounougou. c TCS and tcsBU haplotype network showing a low polymorphism in exon 20. d Phylogenetic tree analysis of VGSC. Green dots represent the susceptible haplotype, and the lone red dot the resistant haplotype

negative values, but they were not significant (Table 2). Four of the haplotypes ( $\mathrm{H} 1, \mathrm{H} 3, \mathrm{H} 4$ and $\mathrm{H} 5)$ contained the 1014L susceptible allele, and surprisingly one haplotype harbored the $1014 \mathrm{~S}$ resistant allele (Fig. 6d), leading to a low $1014 \mathrm{~S} k d r$ frequency of $3.57 \%(1 / 28)$. Haplotype H1 was the only major haplotype carrying the $1014 \mathrm{~L}$ susceptible allele at a high frequency of $85.71 \%(24 / 28)$ among the identified haplotypes (Fig. 6a-c). Genetic parameters for the analysis of this fragment of VGSC are summarized in Table 2.

Phylogenetic analysis also established the presence of three haplotypes H3, H4 and H5 carrying 1014L susceptible allele, derived from single or two mutational steps from the predominant haplotype $\mathrm{H} 1$ (Fig. 6d). Haplotype $\mathrm{H} 2$ containing the $1014 \mathrm{~S}$ resistant allele is the most isolated to the major haplotype $\mathrm{H} 1$ with three mutational steps.

\section{Discussion}

Composition of the local An. gambiae (s.l.) populations and their role in malaria transmission

In this study we established the role of the major malaria vector $A n$. coluzzii from northern Cameroon in malaria transmission and characterized its insecticide resistance profile. Anopheles coluzzii and An. arabiensis were the only members of $A n$. gambiae species complex obtained at Gounougou. Anopheles coluzzii was the most prevalent species from indoor resting collection, whereas $A n$. arabiensis was found at low frequency. It has been reported that at the height of the rainy season (August) An. coluzzii is usually the most dominant species, while in the dry season An. gambiae (s.s.) and $A n$. funestus are the most dominant [15, 26, 43]. The findings of a higher proportion of An. coluzzii 
indoors might perhaps be explained from observations of the more synanthropic nature and endophilic tendency of this species compared to An. arabiensis, which is known to exhibit more exophilic behavior [44]. The predominance of An. coluzzii in Gounougou, in the rainy season, is in-line with recent observations across Sudan/Guinean savanna in West and Central Africa, e.g. as observed in Sudan savanna in Auyo, Nigeria [45], in Guinea savannah of Kome, southern Chad [46], at the village of Goden in Sudanese-savanna of Burkina Faso [47] and in Alibori, northern Benin [48].

Plasmodium falciparum was the only malaria parasite species detected, at a low rate, in An. coluzzii, suggesting low malaria transmission at this site. However, this infection rate is higher than that obtained in 2014 in An. coluzzii from Tiko, South-West region of Cameroon [7], but lower than that obtained in 2016 in An. coluzzii from Bangui, in Central African Republic [49]. However, a longitudinal survey is needed to establish the contribution of this vector to malaria transmission in this area.

\section{Pattern of insecticide resistance}

A study in 2005 in three sites near Gounougou found that An. arabiensis and An. gambiae (s.s.) (the S molecular form) were resistant to deltamethrin, permethrin and DDT, but completely susceptible to chlorpyrifos-methyl and propoxur [13]. In 2006, An. arabiensis and An. gambiae (s.s.) from the irrigated area of Gounougou were also described to be resistant to lambda-cyhalothrin and deltamethrin, but fully susceptible to fenitrothion and propoxur [26]. Another study in Pitoa, in 2011 described An. arabiensis and gambiae (s.s.) resistant to permethrin, deltamethrin and DDT at increased levels compared to that reported in 2009 [28]. However, in recent years there has been a possible shift in vector composition, with a rise of An. coluzzii populations in place of An. arabiensis, and predominance of An. funestus as observed in recent studies (e.g. [15]) and our work. This shift is also followed with increased pyrethroid resistance and development of resistance towards the non-pyrethroid insecticides [50].

The continuous distribution of LLINs in Cameroon, especially in 2011 and 2016, has resulted in a gradual increase in resistance to pyrethroids/DDT, as reported in Gounougou [19, 51]. The pyrethroids/DDT resistance has become extreme in this major malaria vector. However, this species is found exhibiting full susceptibility to carbamate (bendiocarb and propoxur) and to organophosphate (malathion and fenitrothion), as previously reported in An. gambiae (s.l.) [26, 27], suggesting that insecticides of these classes will be preferable for potential IRS campaigns. The focus should be shifted to organophosphates (e.g. malathion and fenitrothion) and carbamates (e.g. bendiocarb and propoxur) as alternatives for IRS campaign in Gounougou and neighboring regions sharing a similar ecological setting.

The level pyrethroid and DDT resistance observed in the Gounougou An. coluzzii population is higher than resistance in An. gambiae (s.l.) reported in other locations with similar geographical characteristics: in Kome, southern Chad (permethrin, 26.7\% mortality, deltamethrin, 25.4\% and DDT, 41.7\%); in Auyo, northern Nigeria (deltamethrin, $78.4 \%$ mortality and DDT, $44 \%$ ); and in Djenne, central Mali (deltamethrin, 16\% mortality and DDT, 42\%) [44, 45, 52]. This increase may be associated with insecticide selective pressure imposed by the introduction of ITNs in Gounougou since 2006, and LLINs since 2015, as observed in the Sudan/Sahelian-zone of Burkina Faso [53]. Another possible explanation of selective pressure at larval level is attributed to the extensive use of insecticide in cotton-growing area communicating with rice farms field throughout the channel of rain runoff [26].

Bioassays were used to quantify the strength of the resistance and make an association of this strength to the effectiveness of current LLINs as vector control tools. The resistance intensity towards deltamethrin was very high in the Gounougou An. coluzzii population producing a very high resistance ratio; this was higher than that established for the previously characterized Tororo and Tiofora populations $[54,55]$

The finding of susceptibility to carbamate and organophosphate insecticides is generally consistent with the relatively widespread susceptibility of malaria vector populations to these insecticide classes, especially the organophosphates, as observed in West and Central Africa [26, 56-58].

The results of cone assays in this study revealed a considerable loss of efficacy of the LLINs. This finding of reduced efficacy of combination LLINs containing PBO, such as Olyset ${ }^{\circledR}$ Plus is consistent with results obtained recently in Mibellon in the Adamawa region of Cameroon [50], in which a high levels of resistance in An. funestus and An. gambiae populations to pyrethroids were correlated with the loss of efficacy of bednets containing insecticides and/or synergists under laboratory conditions. The PBO-containing bednets, e.g. PermaNet ${ }^{\circledR} 3.0$ usually increase recovery of mortality for most malaria vectors. The low recovery of mortality from exposure to the roof of PermaNet ${ }^{\circledR} 3.0$ is first of its kind in An. coluzzii from Gounougou, and in contrast with previous findings in other African countries [54, 59, 60]. This drastic reduction in efficacy of PermaNet ${ }^{\circledR} 3.0$ may be due to selection pressure from massive distribution of combination bednets. The low mortality of An. coluzzii observed even with PBO combined with permethrin (Olyset ${ }^{\circledR}$ Plus) and deltamethrin (Permanet ${ }^{\circledR} 3.0$ roof) suggests possible 
alternative mechanisms for efficient detoxification of the $\mathrm{PBO}$ itself, or other major non-P450 detoxification genes driving the pyrethroid/DDT resistance in the field.

\section{Contribution of target site insensitivity mutations to the pyrethroid and DDT resistance}

The high resistance to permethrin, deltamethrin and DDT observed in $\mathrm{F}_{1}$ and $\mathrm{F}_{2}$ progenies of An. coluzzii could be linked with the high frequency of the L1014F $k d r$ mutation (65.25\%) established in the $\mathrm{F}_{0}$ parents. However, due to high resistance (low number of dead mosquitoes) phenotype-genotype correlation was not assessed. The $1014 \mathrm{~F} k d r$ mutation has been previously identified in An. arabiensis and An. coluzzii in Gounougou, and in the neighboring locality of Pitoa, in North Cameroon, at lower frequencies [27, 28]. The frequency of the L1014F $k d r$ mutation in Gounougou An. coluzzii is consistent with previous results in countries bordering Cameroon, e.g. northern Nigeria where a $1014 \mathrm{~F} k d r$ mutation frequency of $83 \%$ was reported [45], and in Central African Republic, with 52.3\% for the 1014F resistant allele [49].

The low genetic diversity observed in the partial fragment of the VGSC spanning exon 20, harboring the L1014F codon, suggests a restricted polymorphism of VGSC, highlighted by the very low number of haplotypes, as the $1014 \mathrm{~F}$ allele nears fixation in this population. Our findings are consistent with previous studies reported in Central Africa [49, 60]. The fact that the predominant haplotype $\mathrm{H} 3$ matched with that found across Africa (H1-1014F) suggests a gene flow in An. coluzzii populations across the region.

\section{Conclusions}

This study provides evidence for drastically high pyrethroid and DDT resistance in An. coluzzii, a major malaria vector from Gounougou, northern Cameroon, with the possibility of a complete loss of efficacy of the major malaria control tools, the LLINs and IRS using DDT. The intense resistance is driven possibly by metabolic mechanism and the 1014F $k d r$ mutation which was found in high frequency.

\footnotetext{
Abbreviations

DDT: dichlorodiethyltrichloroethane; DNA: deoxyribonucleic acid; DnaSP: DNA sequence polymorphism; dNTPs: deoxyribonucleoside triphosphates; GSTe2: glutathione S-transferase epsilon 2; IRS: indoor residual spraying; ITN: insecticide-treated net; kdr: knockdown resistance mutation; LLIN: long-lasting insecticidal net; LT: lethal time; MEGA: Molecular Evolutionary Genetics Analysis; PBO: piperonyl butoxide; PCR: polymerase chain reaction; s.I.: sensu lato; s.s.: sensu stricto; VGSC: voltage-gated sodium channel.
}

\section{Acknowledgements}

This study was supported by the Wellcome Trust International Fellowship in Public Health (WT201918/Z/16/Z) to SSI. The authors would like to thank the people of Gounougou for welcoming us into their homes.

\section{Authors' contributions}

CSW, SSI and SW conceived and designed the study. SSI, ANF and MaT performed sample collection at Gounougou. ANF, MaT and ET carried out bioassays. ANF carried out the TaqMan genotyping and polymorphism analyses of the VGSC, with the help of MJW and MiT. ANF and SSI analysed data and wrote the manuscript with help from CSW. All authors read and approved the final manuscript.

\section{Funding}

A Wellcome Trust International Training Fellowship in Public Health and Tropical Medicine (WT201918/Z/16/Z) to SSI supported this work.

\section{Availability of data and materials}

The datasets (DNA sequences) supporting the conclusions of this article are available in the GenBank database under the accession numbers MK548913MK548927 for An. coluzzii sequences and MK548928-MK548941 for An. arabiensis sequences.

\section{Ethics approval and consent to participate}

Clearance for field work and ethical approval was granted by the Organisation de Coordination pour la lutte contre les Ende'mies en Afrique Centrale (OCEAC) (authorisation number 0520/17/SE/DAF). Prior to collection, a meeting was held with the local chief and the village people at Gounougou to explain the aim of the study and its benefits. Indoor collection was carried out only in the houses of people who consented.

\section{Consent for publication}

Not applicable.

\section{Competing interests}

The authors declare that they have no competing interests.

\section{Author details \\ ${ }^{1}$ LSTM Research Unit, Centre for Research in Infectious Diseases (CRID), P.O. Box 13591, Yaoundé, Cameroon. ${ }^{2}$ Department of Microbiology and Parasitol- ogy, University of Buea, P.O. Box 63, Buea, Cameroon. ${ }^{3}$ Vector Biology Depart- ment, Liverpool School of Tropical Medicine (LSTM), Liverpool L3 5QA, UK. \\ ${ }^{4}$ Department of Biochemistry, Bayero University, PMB 3011, Kano, Nigeria.}

Received: 23 February 2019 Accepted: 20 May 2019

Published online: 27 May 2019

References

1. WHO. World Malaria Report 2018. Geneva: World Health Organization; 2018.

2. WHO. World Malaria Report 2017. Geneva: World Health Organization; 2018.

3. Hemingway J, Ranson H, Magill A, Kolaczinski J, Fornadel C, Gimnig J, et al. Averting a malaria disaster: will insecticide resistance derail malaria control? Lancet. 2016;387:1785-8.

4. Ranson H, Lissenden N. Insecticide resistance in African Anopheles mosquitoes: a worsening situation that needs urgent action to maintain malaria control. Trends Parasitol. 2016;32:187-96.

5. Antonio-Nkondjio C, Kerah CH, Simard F, Awono-Ambene P, Chouaibou M, Tchuinkam T, et al. Complexity of the malaria vectorial system in Cameroon: contribution of secondary vectors to malaria transmission. J Med Entomol. 2006;43:1215-21.

6. Massoda Tonye SG, Kouambeng C, Wounang R, Vounatsou P. Challenges of DHS and MIS to capture the entire pattern of malaria parasite risk and intervention effects in countries with different ecological zones: the case of Cameroon. Malar J. 2018;17:156.

7. Amvongo-Adjia N, Wirsiy EL, Riveron JM, Ndongmo WPC, Enyong PA, Njiokou F, et al. Bionomics and vectorial role of anophelines in wetlands along the volcanic chain of Cameroon. Parasit Vectors. 2018;11:471.

8. Walker-Abbey A, Djokam RRT, Eno A, Leke RFG, Titanji VPK, Fogako J, et al. Malaria in pregnant Cameroonian women: the effect of age and gravidity on submicroscopic and mixed-species infections and multiple parasite genotypes. Am J Trop Med Hyg. 2005;72:229-35. 
9. Songue E, Tagne C, Mbouyap P, Essomba P, Somo RM. Epidemiology of malaria in three geo-ecological zones along the Chad-Cameroon pipeline. Am J Epidemiol Infect Dis. 2013;1:27-33.

10. Roman DNR, Rosalie NNA, Kumar A, Luther KMM, Singh V, Albert MS Asymptomatic Plasmodium malariae infections in children from suburban areas of Yaoundé, Cameroon. Parasitol Int. 2018;67:29-33.

11. Ndo C, Kopya E, Donbou MA, Njiokou F, Awono-Ambene P, Wondji C. Elevated Plasmodium infection rates and high pyrethroid resistance in major malaria vectors in a forested area of Cameroon highlight challenges of malaria control. Parasit Vectors. 2018;11:157.

12. Wondji C, Simard F, Petrarca V, Etang J, Santolamazza F, Torre AD, et al. Species and populations of the Anopheles gambiae complex in Cameroon with special emphasis on chromosomal and molecular forms of Anopheles gambiae s.s. J Med Entomol. 2005:42:998-1005.

13. Chouaïbou M, Etang J, Brévault T, Nwane P, Hinzoumbé CK, Mimpfoundi $R$, et al. Dynamics of insecticide resistance in the malaria vector Anopheles gambiae s/ from an area of extensive cotton cultivation in Northern Cameroon. Trop Med Int Health. 2008;13:476-86.

14. Nwane P, Etang J, Chouaïbou M, Toto J, Mimpfoundi R, Simard F. Kdrbased insecticide resistance in Anopheles gambiae s.s. populations in. BMC Res Notes. 2011;4:463.

15. Menze BD, Riveron JM, Ibrahim SS, Irving H, Antonio-Nkondjio C, AwonoAmbene $\mathrm{PH}$, et al. Multiple insecticide resistance in the malaria vector Anopheles funestus from Northern Cameroon is mediated by metabolic resistance alongside potential target site insensitivity mutations. PLoS ONE. 2016;11:10.

16. Tabue RN, Awono-Ambene P, Etang J, Atangana J, Antonio-Nkondjio C, Toto JC, et al. Role of Anopheles (Cellia) rufipes (Gough, 1910) and other local anophelines in human malaria transmission in the northern savannah of Cameroon: a cross-sectional survey. Parasit Vectors. 2017;10:22.

17. Awono-Ambene PH, Etang J, Antonio-Nkondjio C, Ndo C, Eyisap WE, Piameu MC, et al. The bionomics of the malaria vector Anopheles rufipes Gough, 1910 and its susceptibility to deltamethrin insecticide in North Cameroon. Parasit Vectors. 2018;11:253.

18. Ayala D, Costantini C, Ose K, Kamdem GC, Antonio-Nkondjio C, Agbor JP, et al. Habitat suitability and ecological niche profile of major malaria vectors in Cameroon. Malar J. 2009;8:307

19. Antonio-Nkondjio C, Sonhafouo-Chiana N, Ngadjeu CS, Doumbe-Belisse P, Talipouo A, Djamouko-Djonkam L, et al. Review of the evolution of insecticide resistance in main malaria vectors in Cameroon from 1990 to 2017. Parasit Vectors. 2017;10:472.

20. Kamdem C, Tene Fossog B, Simard F, Etouna J, Ndo C, Kengne P, et al. Anthropogenic habitat disturbance and ecological divergence between incipient species of the malaria mosquito Anopheles gambiae. PLoS ONE. 2012; $7:$ e39453

21. Kamdem C, Fouet C, Gamez S, White BJ. Pollutants and insecticides drive local adaptation in African malaria mosquitoes. Mol Biol Evol. 2017;34:1261-75.

22. Bhatt S, Weiss DJ, Cameron E, Bisanzio D, Mappin B, Dalrymple U, et al. The effect of malaria control on Plasmodium falciparum in Africa between 2000 and 2015. Nature. 2015:526:207-11.

23. President's Malaria Initiative. Cameroon Malaria Operational Plan FY 2017. 2017. https://www.pmi.gov/docs/default-source/default-document-libra ry/malaria-operational-plans/fy17/fy-2017-cameroon-malaria-operationa I-plan.pdf?sfvrsn=6. Accessed 12 May 2018.

24. Müller P, Chouaïbou M, Pignatelli P, Etang J, Walker ED, Donnelly MJ, et al. Pyrethroid tolerance is associated with elevated expression of antioxidants and agricultural practice in Anopheles arabiensis sampled from an area of cotton fields in Northern Cameroon. Mol Ecol. 2008;17:1145-55.

25. Etang J, Fondjo E, Chandre F, Morlais I, Brengues C, Nwane P, et al. Short report: first report of knockdown mutationsin the malaria vector Anopheles gambiae from Cameroon. Am J Trop Med Hyg. 2006;74:795-7.

26. Antonio-Nkondjio C, Atangana J, Ndo C, Awono-Ambene P, Fondjo E, Fontenille D, et al. Malaria transmission and rice cultivation in Lagdo, northern Cameroon. Trans R Soc Trop Med Hyg. 2008;102:352-9.

27. Ndjemaï HNM, Patchoké S, Atangana J, Etang J, Simard F, Bilong CFB, et al. The distribution of insecticide resistance in Anopheles gambiae s.l. populations from Cameroon: an update. Trans R Soc Trop Med Hyg. 2009;103:1127-38.

28. Etang J, Pennetier C, Piameu M, Bouraima A, Chandre F, Awono-Ambene $P$, et al. When intensity of deltamethrin resistance in Anopheles gambiae s.l. leads to loss of long-lasting insecticidal nets bio-efficacy: a case study in north Cameroon. Parasit Vectors. 2016;9:132.

29. Morgan JC, Irving H, Okedi LM, Steven A, Wondji CS. Pyrethroid resistance in an Anopheles funestus population from uganda. PLOS ONE. 2010;5(7):e11872.

30. Gillies M, de Meillon D. The Anophelinae of Africa south of the Sahara (Ethiopian zoogeographical region). Publ South Afric Inst Med Res. 1968;54:1-353.

31. Gillies MT, Coetzee M. A supplement to the Anophelinae of Africa South of the Sahara (Afrotropical Region). Publ South African Inst Med Res. 1987;55:1-143.

32. Livak KJ. Organization and mapping of a sequence on the Drosophila melanogaster $X$ and $Y$ chromosomes that is transcribed during spermatogenesis. Genetics. 1984;107:611-34.

33. Santolamazza F, Mancini E, Simard F, Qi Y, Tu Z, Torre A. Insertion polymorphisms of SINE200 retrotransposons within speciation islands of Anopheles gambiae molecular forms. Malar J. 2008;7:163.

34. Bass C, Nikou D, Blagborough AM, Vontas J, Sinden RE, Williamson MS, et al. PCR-based detection of Plasmodium in Anopheles mosquitoes: a comparison of a new high-throughput assay with existing methods. Malar J. 2008;7:177

35. Snounou G, Viriyakosol S, Zhu XP, Jarra W, Pinheiro L, do Rosario VE, et al. High sensitivity of detection of human malaria parasites by the use of nested polymerase chain reaction. Mol Biochem Parasitol. 1993;61:315-20.

36. WHO. Test procedures for insecticide resistance monitoring in malaria vector mosquitoes. World Health Organisation Technical Report Series. 2nd edn. Geneva: World Health Organization; 2013.

37. Bass C, Nikou D, Donnelly MJ, Williamson MS, Ranson H, Ball A, et al. Detection of knockdown resistance $(k d r)$ mutations in Anopheles gambiae: a comparison of two new high-throughput assays with existing methods. Malar J. 2007;6:111.

38. Pinto J, Lynd A, Vicente JL, Santolamazza F, Randle NP, Gentile G, et al. Multiple origins of knockdown resistance mutations in the afrotropical mosquito vector Anopheles gambiae. PLoS ONE. 2007:2:e1243.

39. Hall T. BioEdit: A user-friendly biological sequence alignment editor and analysis program for windows 95/98/NT. Nucleic Acids Symp Ser. 1999:41:95-8.

40. Librado P, Rozas J. DnaSP v5: a software for comprehensive analysis of DNA polymorphism data. Bioinformatics. 2009:25:1451-2.

41. Kumar S, Stecher G, Tamura K. MEGA7: molecular evolutionary genetics analysis version 7.0 for bigger datasets. Mol Biol Evol. 2016;33:1870-4

42. Ibrahim SS, Mukhtar MM, Datti JA, Irving H, Kusimo MO, Tchapga W, et al. Temporal escalation of pyrethroid resistance in the major malaria vector Anopheles coluzzii from Sahelo-Sudanian region of northern Nigeria. Sci Rep. 2019. https://doi.org/10.1038/s41598-019-43634-4.

43. Wondji C, Simard F, Lehmann T, Fondjo E, Samè-Ekobo A, Fontenille D. Impact of insecticide-treated bed nets implementation on the genetic structure of Anopheles arabiensis in an area of irrigated rice fields in the Sahelian region of Cameroon. Mol Ecol. 2005;14:3683-93.

44. Mahande A, Mosha F, Mahande J, Kweka E. Feeding and resting behaviour of malaria vector, Anopheles arabiensis with reference to zooprophylaxis. Malar J. 2007:6:100

45. Ibrahim SS, Manu YA, Tukur Z, Irving $H$, Wondji CS. High frequency of $k d r$ L1014F is associated with pyrethroid resistance in Anopheles coluzzii in Sudan savannah of northern Nigeria. BMC Infect Dis. 2014;14:441.

46. Dadzie S, Appawu MA, Kerah-Hinzoumbe C, Akogbeto MC, Adimazoya $\mathrm{M}$, Israel DK, et al. Species composition and insecticide resistance status of Anopheles gambiae (s.l.) (Culicidae) in Kome, southern Chad and the implications for malaria control. Parasit Vectors. 2016;9:465.

47. Pombi M, Calzetta M, Guelbeogo WM, Manica M, Perugini E, Pichler V, et al. Unexpectedly high Plasmodium sporozoite rate associated with low human blood index in Anopheles coluzzii from a LLIN-protected village in Burkina Faso. Sci Rep. 2018;8:12806.

48. Akogbéto MC, Salako AS, Dagnon F, Aïkpon R, Kouletio M, Sovi A, et al. Blood feeding behaviour comparison and contribution of Anopheles coluzzii and Anopheles gambiae, two sibling species living in sympatry, to malaria transmission in Alibori and Donga region, northern Benin, West Africa. Malar J. 2018;17:307.

49. Kamgang B, Tchapga W, Ngoagouni C, Sangbakembi-Ngounou C, Wondji $\mathrm{M}$, Riveron JM, Wondji CS. Exploring insecticide resistance mechanisms 
in three major malaria vectors from Bangui in Central African Republic. Pathog Glob Health. 2018;112:349-59.

50. Menze BD, Wondji MJ, Tchapga W, Tchoupo M, Riveron JM, Wondji CS. Bionomics and insecticides resistance profiling of malaria vectors at a selected site for experimental hut trials in central Cameroon. Malar J. 2018;17:317.

51. World Health Organization. A toolkit for integrated vector management in sub-saharan Africa. 2016. http://apps.who.int/iris/bitstream/handl e/10665/250267/9789241549653-eng.pdf?sequence=1. Accessed 14 May 2018.

52. Cisse MBM, Keita C, Dicko A, Dengela D, Coleman J, Lucas B, et al. Characterizing the insecticide resistance of Anopheles gambiae in Mali. Malar J. 2015;14:327.

53. Dabiré KR, Diabaté A, Namountougou M, Toé KH, Ouari A, Kengne P, et al. Distribution of pyrethroid and DDT resistance and the L1014F kdr mutation in Anopheles gambiae s.l. from Burkina Faso (West Africa). Trans R Soc Trop Med Hyg. 2009;103:1113-20.

54. Toé KH, Jones CM, N'fale S, Ismai HM, Dabiré RK, Ranson H. Increased pyrethroid resistance in malaria vectors and decreased bed net effectiveness Burkina Faso. Emerg Infect Dis. 2014:20:1691-6.

55. Bagi J, Grisales N, Corkill R, Morgan JC, N'Falé S, et al. When a discriminating dose assay is not enough: measuring the intensity of insecticide resistance in malaria vectors. Malar J. 2015;14:210.
56. Kerah-Hinzoumbé C, Péka M, Nwane P, Donan-Gouni I, Etang J, SamèEkobo A, et al. Insecticide resistance in Anopheles gambiae from southwestern Chad, Central Africa. Malar J. 2008;7:192.

57. Ranson H, Abdallah H, Badolo A, Guelbeogo WM, Kerah-Hinzoumbé C, Yangalbé-Kalnoné $\mathrm{E}$, et al. Insecticide resistance in Anopheles gambiae: Data from the first year of a multi-country study highlight the extent of the problem. Malar J. 2009;17:299.

58. Witzig C, Parry M, Morgan JC, Irving H, Steven A, Cuamba N, et al. Genetic mapping identifies a major locus spanning P450 clusters associated with pyrethroid resistance in $k d r$-free Anopheles arabiensis from Chad. Heredity. 2013;110:389-97.

59. Riveron JM, Chiumia M, Menze BD, Barnes KG, Irving H, Ibrahim SS, et al. Rise of multiple insecticide resistance in Anopheles funestus in Malawi: a major concern for malaria vector control. Malar J. 2015;14:344.

60. Riveron JM, Watsenga F, Irving H, Irish SR, Wondji CS. High Plasmodium infection rate and reduced bed net efficacy in multiple insecticide-resistant malaria vectors in Kinshasa, Democratic Republic of Congo. J Infect Dis. 2018;217:320-8.

\section{Publisher's Note}

Springer Nature remains neutral with regard to jurisdictional claims in published maps and institutional affiliations.
Ready to submit your research? Choose BMC and benefit from:

- fast, convenient online submission

- thorough peer review by experienced researchers in your field

- rapid publication on acceptance

- support for research data, including large and complex data types

- gold Open Access which fosters wider collaboration and increased citations

- maximum visibility for your research: over $100 \mathrm{M}$ website views per year

At BMC, research is always in progress.

Learn more biomedcentral.com/submissions 